\title{
Developments and future insights of using nanofluids for heat transfer enhancements in thermal systems: a review of recent literature
}

\author{
Abdul Kaggwa' $^{1} \cdot$ James K. Carson ${ }^{1}$ \\ Received: 3 January 2019 / Accepted: 30 July 2019 / Published online: 9 August 2019 \\ (c) The Author(s) 2019
}

\begin{abstract}
The twenty-first century is experiencing a wave of technologies and innovations making use of unique features of nanofluids, in applications such as industrial and process heating, air conditioning and refrigeration systems, heat pipes, solar energy, thermal storage systems, electronic cooling systems and others. Recent literature indicates that suspending solid nanoparticles in traditional working fluids can enhance heat transfer rates by increasing thermal conductivity and heat transfer coefficients. However, there is a wide variation in the extent of heat transfer enhancements reported in the literature. In this review, which mainly focuses on the research published within the last 5 years, experimental investigations from recent developments of nanofluids usage and performance in various heat transfer systems are summarised. In addition, heat transfer mechanisms in nanofluids, the challenges and future direction of nanofluids regarding heat transfer enhancement are discussed. Popular preparation methods of nanofluids and the models of thermophysical properties such as thermal conductivity and viscosity have been reviewed.
\end{abstract}

Keywords Nanofluids $\cdot$ Heat transfer enhancement $\cdot$ Challenges and heat transfer mechanism $\cdot$ Stability $\cdot$ Review

\section{Introduction}

The knowledge and understanding of heat transfer are important for the design of a wide range of industrial, commercial and domestic processes and appliances, including chemical processing, air conditioning and refrigeration, solar energy production and conversion, oil and gas industries and electronics cooling. In thermal engineering, the improvement in the thermal performance of systems is termed 'heat transfer enhancement'. Over the past decade, several techniques have been proposed as ways of enhancing heat transfer [1-3]. These techniques have been classified as passive or active (Table 1).

Figure 1 shows thermal conductivities of different materials. Since the thermal conductivity of solids may be several orders of magnitude higher than the thermal conductivities of conventional heat transfer fluids such as water, oil or ethylene glycol (EG), the addition of highly conducting solid

Abdul Kaggwa

Kaggwaabu@ymail.com

1 School of Engineering, Faculty of Science and Engineering, University of Waikato, Private Bag 3105, Hamilton 3240, New Zealand particles to a fluid has the potential to increase the effective thermal conductivity of the fluid.

Choi and Eastman [5] introduced the term "nanofluids" to describe suspensions of copper nanoparticles in water. Their investigations revealed that the thermal conductivity of the fluid was enhanced by a factor of 1.5 and 3.5 compared to water at low volume fractions of $5 \%$ and $20 \%$, respectively. Further experiments with copper nanoparticles in acidified ethylene glycol showed apparently anomalous increases in thermal conductivity [6]. However, they also observed that the thermal conductivity of copper/ethylene-glycol nanofluids decreased with time, which was most likely due to agglomeration and/or sedimentation of the nanoparticles.

Similar encouraging results were observed by other researchers and subsequently the use of nanofluids for heat transfer enhancement became a very active area of research [7-11]. However, to date, it does not appear that nanofluids have received widespread usage outside the research environment. In practice, the usage of nanoparticles in heat transfer equipment still faces a number of challenges arising from issues such as (1) lack of stability of the nanofluids, (2) high variation on reported physical properties and heat transfer enhancement effects in the literature, (3) lack of understanding about the mechanisms and forces that act on 
Table 1 Passive and active heat transfer enhancement techniques [4]

\begin{tabular}{ll}
\hline Passive & Active \\
\hline Treated surfaces & Mechanical aids \\
Rough surfaces & Surface vibration \\
Extended surfaces & Fluid vibration \\
Displaced enhancement devices & Electrostatic fields \\
Swirl flow devices & Injection \\
Coiled tubes & Suction \\
Surface tension devices & Jet impingement \\
Additives for liquids & \\
Additives for gases & \\
\hline
\end{tabular}

the nanoparticles during and after suspension. These issues have slowed the process of standardisation and formulation of nanofluid technology. The aim of this paper is to review the recent developments and the future prospects for nanofluids in heat transfer systems.

\section{Preparation of nanofluids}

Nanoparticles used in nanofluids range in size from 1 to $100 \mathrm{~nm}$ and different shapes such as nanospheres (spherical), nanoreefs, nanoboxes, nanoclusters and nanotubes. Some studies [12-15] have concluded that the morphology of nanoparticles is defined during synthesis, and the average size of nanoparticles plays a significant role in the enhancement of thermal conductivity a primary factor for heat transfer enhancement.

There are two popular methods used in the preparation of nanofluids: the single-step method and the two-step method [16] as shown in Fig. 2. The single-step method involves the simultaneous production of nanoparticles and suspension of the particles into the base fluid. For example, the nanoparticles may be formed by condensation from the vapour phase directly into the heat transfer liquid. This method has the advantage of producing minimal nanoparticle agglomeration; however, it is characterised by high costs, and is
Fig. 1 Thermal conductivity of some heat transfer materials
Thermal conductivity of heat transfer materials

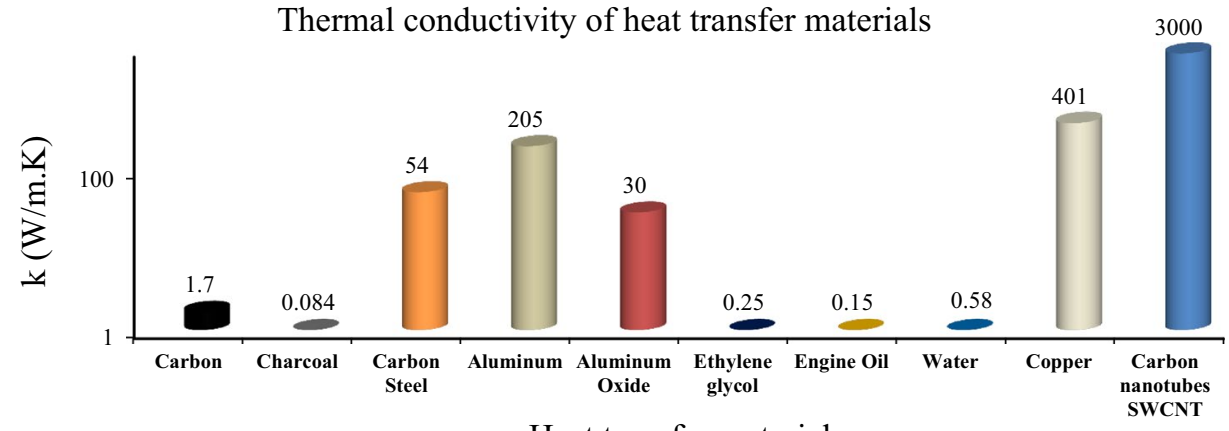

Heat transfer materials
Fig. 2 Methods of nanofluids preparation

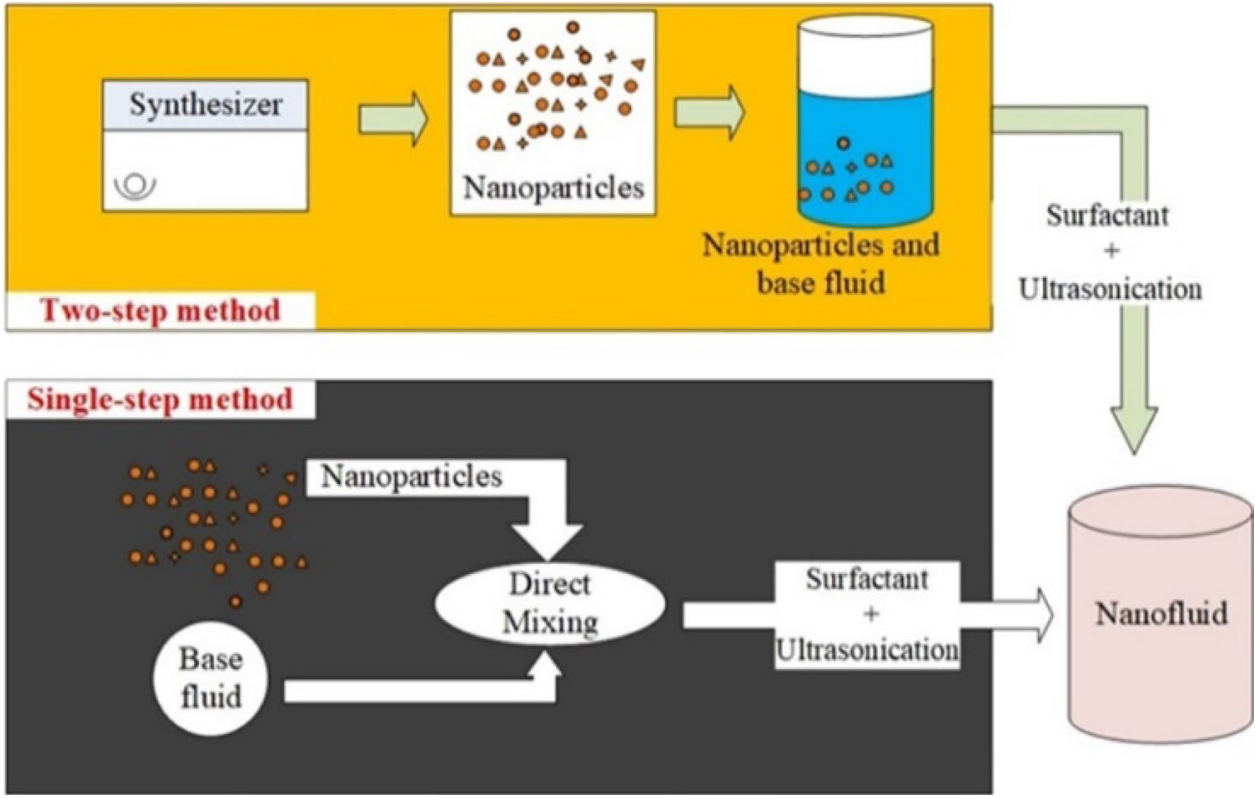


therefore likely to be infeasible on an industrial scale. In contrast, in the two-step method, nanoparticles are produced in a separate process before being dispersed into the base fluid [17]. Stabilising agents such as surfactants can be added to reduce the interfacial forces between the nanoparticles and base fluid molecules. Subsequently, the solution may be mixed using mechanical devices such as homogeniser, stirrer and ultrasonicator. The two-step method appears to have received the most widespread use, since it is generally less labour intensive and more cost effective [17-19].

\section{Mechanism of heat transfer enhancement in nanofluids}

Maxwell [20] proposed a model for determining the electrical conductivity of a dispersion of spheres in a continuous medium that has subsequently been applied successfully to the prediction of thermal conductivities of heterogeneous materials [21, 22]. Maxwell's model and derivatives may be thought of as 'classic theory' for thermal conductivity modelling [23]. However, the rise in popularity of nanofluids has largely been due to reports of experimentally determined thermal conductivities being many times higher than those predicted by classic theory [24, 25]. In the open literature, there does not appear to be any single theory that can explain the apparently anomalous heat transfer enhancement effects in nanofluids that have been reported by some researchers $[6,26]$. However, a variety of mechanisms have been proposed. For instance, in a review of metal-oxide nanoparticles Suganthi et al. [27] concluded that Brownian motion plays a significant role in increasing thermal conductivity of nanofluids. The stochastic movement of nanoparticles in a fluid depends on temperature, diameter of the particles and viscosity of the fluid. Farzaneh et al. [28] suggested that in addition to Brownian motion, nanoparticles once suspended also experience drag, thermophoresis, Van der Waals and electric double layer forces. The study added that a combination of inter-particle Van der Waals and electric double layer forces produces a combined force called "DLVO", which together with other forces play a significant role in the mechanism of heat transfer in nanofluids.

Kang et al. [29] proposed a mechanism based on the cross coupling of thermal and electric transports in nanofluids. They explained that due to the fact that nanoparticles have surface charges, a varying electric field can be generated to accompany the particle thermal motion. Therefore, the base fluid is heated by the nanoparticles through molecular collision such that the nanoparticles may be considered as an internal heat source.

Sanukrishna et al. [30] reported that the mechanism of molecular layer formation inside evaporator tubes during evaporation could be the reason for heat transfer enhancement in two-phase flow boiling.

However, to date, none of these theories have been used to produce models that can accurately predict heat transfer enhancement across a wide range of applications.

\section{Thermophysical properties of nanofluids}

The thermal properties that affect conduction and convection include thermal conductivity, specific heat capacity, density and viscosity. Therefore, any heat transfer model requires accurate thermal property data. For specific heat capacity and density, it is often assumed that a weighted arithmetic mean of the components' base fluid and nanoparticle densities or specific heat capacities can provide accurate predictions of the nanofluids density or specific heat capacity. However, determining the thermal conductivity and viscosity of nanofluids is not as straightforward.

\section{Thermal conductivity}

Thermal conductivity is the most studied transport property in nanofluids, as it is commonly assumed that the significant increases in heat transfer rates observed with nanofluids are primarily caused by the increased thermal conductivity. For nanofluids, common thermal conductivity measurement methods include the transient hot-wire device [31] or the thermal property analyser [32].

Hemmat Esfe et al. [33] studied the efficiency of ferromagnetic nanoparticles suspended in ethylene glycol. They focussed on the effect of particle size, temperature and concentration to determine the thermal conductivity and viscosity of the nanofluids with volume fraction of up to $3 \%$ in the temperature range of $26-55{ }^{\circ} \mathrm{C}$. Their results showed that the efficiency of nanofluids increased with an increase in the temperature and solid volume fraction. They also concluded that the optimum particle size depended on the flow regime (i.e. the laminar vs. turbulent).

Deepak et al. [15] developed a model to predict the thermal conductivity of nanofluids based on particle size distribution and multi-level homogenization. They mainly focused on the effects of Brownian motion, interfacial layer formation and particle clustering. Similarly, Lee et al. [12] reported that the efficiency of nanofluids was improved by increasing particle size and temperature. However, particle size variation was more noticeable than temperature variation for thermal conductivity and viscosity measurements.

Ueki et al. [34] conducted an experiment on thermophysical properties of carbon-based material nanofluid. They concluded that nanoparticle geometry and temperature influenced thermal conductivity. In addition, they found out 
that carbon black and carbon nanopowder enhanced thermal conductivity by $7 \%$ and $19 \%$, respectively.

Lenin and Roy [35] reported that the critical concentration for thermal conductivity enhancement varies with the surfactant used, possibly due to the difference in the degree of aggregation of the nanoparticles and conformation of the surfactant molecules on the nanoparticle's surface. They added that base fluids with lower thermal conductivity and dielectric constant showed larger enhancement in the thermal conductivity relative to base fluids with higher thermal conductivities.

However, despite the many positive results, Hussein et al. [36] found that the effect of volume fraction, temperature and the size diameter on friction is not clearly elaborated in the literature yet, it is vital for developing correlations of thermal properties of nanoparticles. A large number of thermal conductivity models that have been proposed (examples shown in Tables 2,3), some of which consider the morphology of nanoparticles, assume that all particles are spherical and introduce a variety of (mostly empirical) constants. Therefore, it is difficult to know which model should be used for particular nanofluids. To demonstrate, Fig. 3 shows predictions from the classical model of Maxwell [20], that are compared to those of Buongiorno et al. [37] and Maiga et al. [38] showing significant differences. Yang et al. [39] explained that factors such as particle parameters (particle
Table 2 Summary of models for thermal conductivity of nanofluids

Table 3 Summary of measured thermal conductivity data of nanofluids

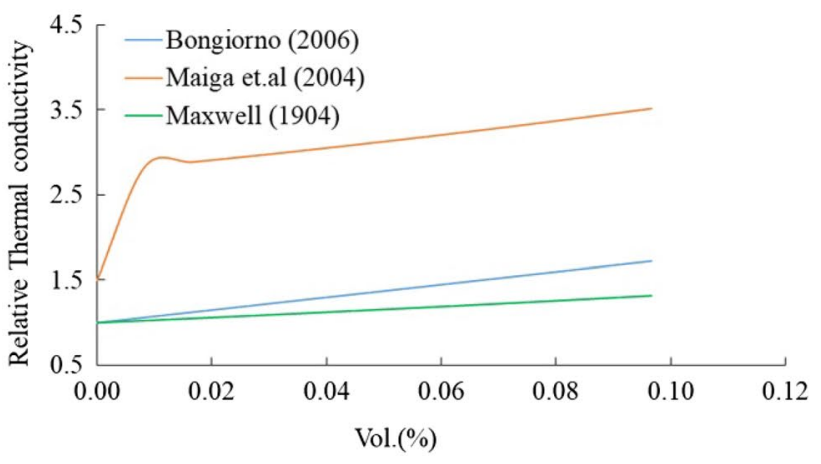

(a)

\begin{tabular}{lll}
\hline Author & Empirical model & Remarks \\
\hline Maxwell [20] & $K_{n f}=\left[\frac{K_{p}+K_{b f}+2 \phi\left(K_{p}-K_{b f}\right)}{K_{p}+K_{b f}+\phi\left(K_{p}-K_{b f}\right)}\right] K_{b f}$ & Volume fraction of solid spherical particles \\
Pak and Cho [81] & $K_{n f}=(1+7.74 \phi) K_{b f}$ & Depends on spherical and non-spherical particles \\
Maiga et al. [38] & $K_{n f}=\left(1+4.97 \phi^{2}+2.72 \phi\right) K_{b f}$ & Considered spherical particles \\
Boungiorno [37] & $K_{n f}=\left(1+2.92 \phi-11.99 \phi^{2}\right) K_{b f}$ & Titania spherical and non-spherical particles \\
Mintsa et al. [82] & $K_{n f}=(1+1.7 \phi) K_{b f}$ & -
\end{tabular}

\begin{tabular}{llll}
\hline Author & Nanofluid & Temperature $\left({ }^{\circ} \mathrm{C}\right)$ & Enhancement (\%) \\
\hline Ueki et al. [35] & Carbon nanopowder-water & 20 & 19 \\
& Carbon black-water & & 7 \\
Jiang et al. [25] & Ammonia-water & 120 & $3-12$ \\
Murshed et al. [83] & $\mathrm{TiO}_{2}$-water & - & $30-33$ \\
Parametthanuwat et al. [84] & $\mathrm{Ag}^{- \text {water }}$ & $20-80$ & 80 \\
Hafiz et al. [85] & $\mathrm{TiO}_{2-\text { water }}$ & 29.4 & 15.87 \\
Karimi et al. [86] & $\mathrm{NiFe}_{2} \mathrm{O}_{4}$ water & $25-55$ & 17.2 \\
Mehrail et al. [87] & $\mathrm{Nitrogen-doped} \mathrm{graphene-water}^{-5-40}$ & $22.15-36.78$ \\
Kole et al. [88] & Graphene-EG/water & $10-70$ & 15 \\
Branson et al. [89] & NanoDiamond-EG & $10-80$ & $11-12$ \\
\hline
\end{tabular}

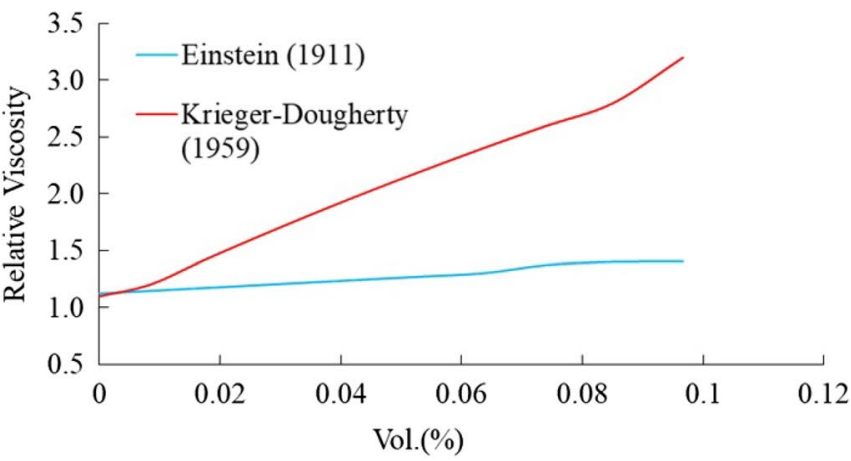

(b)

Fig. 3 The effect of nanoparticle concentration on thermal conductivity (a) and viscosity (b) using different models for carbon-water nanofluid 
type, loading, size and shape) and environmental parameters (base fluid, $\mathrm{pH}$ value, temperature and the standing time) influence thermal conductivity. These aforementioned factors as well as preparation methods could be significant causes of the discrepancy in thermal conductivity enhancement reported in the literature.

\section{Viscosity}

In their landmark paper, Choi and Eastman [5] assumed that the addition of nanoparticles would not significantly affect the viscosity of the nanofluids; however, this is not necessarily the case. For example, Namburu et al. [40] measured the viscosity of copper oxide nanoparticles dispersed in a mixture of ethylene glycol and water and found that the viscosity of $6.12 \%$ volume concentration of the nanofluids was four times the value of the base fluid. In addition, they concluded that the viscosity of nanofluids increases with increasing amounts of nanoparticles. Similarly, Hemmat et al. [41] found that the viscosity of zinc-oxide/ethylene glycol nanofluids increased considerably with particle volume concentration significantly, as did Mariano et al. [42] and Yu et al. [43], who also made the point that heat transfer enhancement effects of the nanofluid were offset by the increased pumping power requirements.

It is also possible that the addition of nanoparticles and/or surfactants may cause the nanofluids to behave in a non-Newtonian manner, even though the base fluid may be Newtonian. While, Mariano et al. [42] reported that the viscosity of the nanofluids is 'nearly independent' of the shear rate, Kaggwa et al. [44] observed that the viscosity of carbon-water nanofluids decreased with an increase in shear rate and the viscosity of carbon-hexane nanofluids increased with the increase in shear rate. They concluded that base fluids, nanoparticle concentration as well as surfactants have a significant effect on viscosity measurements.

It can be difficult to model the viscosity of nanofluids. To illustrate, Fig. 3b shows two different viscosity models, the popular Einstein [45] model for mixture viscosity and the Krieger-Dougherty [46] model for nanofluids that produce widely differing predictions. The discrepancy between predictions is due to a number of factors. For example, Einstein [45] assumed the particles to be rigid, uncharged and devoid of any attractive forces and in low concentration, whereas Krieger-Dougherty [46] considered the full range of particle volume fractions, the influence of aggregation and the formation of interfacial layers.

As with thermal conductivity, the viscosity of nanofluids remains to be an area requiring further investigation, particularly as the effect of the surfactant on viscosity is not always taken into consideration or reported in viscosity studies (Tables 4, 5).

\section{Potential applications of nanofluids}

\section{Solar applications}

As society makes attempts to combat climate change and provide sustainable energy access for all, solar energy stands out as a primary means of reducing global carbon emissions to the Earth's atmosphere. In fact, Lewis et al. [47] pointed out that more energy from sunlight strikes the Earth in $1 \mathrm{~h}$ $(4.3 \times 1020 \mathrm{~J})$ than all the energy consumed on the planet in

Table 5 Summary of measured viscosities of nanofluids

\begin{tabular}{|c|c|c|c|}
\hline Author & Nanofluid & $\begin{array}{l}\text { Temperature } \\
\left({ }^{\circ} \mathrm{C}\right)\end{array}$ & Viscosity ratio \\
\hline $\begin{array}{l}\text { Namburu et al. } \\
{[40]}\end{array}$ & $\mathrm{CuO}-\mathrm{EG}$ & -30 to 50 & 6.12 \\
\hline $\begin{array}{l}\text { Mariano et al. } \\
\text { [42] }\end{array}$ & $\mathrm{Co}_{3} \mathrm{O}_{4}-\mathrm{EG}$ & $10-50$ & 40 \\
\hline $\begin{array}{l}\text { Hemmat et al. } \\
\text { [41] }\end{array}$ & $\mathrm{ZnO}-\mathrm{EG}$ & 50 & 30 \\
\hline Yu et al. [43] & $\begin{array}{l}\mathrm{SiC} \text {-water } \\
\mathrm{Al}_{2} \mathrm{O}_{3} \text {-water }\end{array}$ & $25-70$ & $\begin{array}{l}8 \\
6\end{array}$ \\
\hline Jiang et al. [25] & $\begin{array}{l}\text { Ammonia- } \\
\text { water }\end{array}$ & 120 & $2-7$ \\
\hline He et al. [93] & $\mathrm{TiO}_{2}$-water & 22 & 11 \\
\hline Ding et al. [94] & CNT-water & $25-40$ & - \\
\hline Das et al. [95] & $\mathrm{Al}_{2} \mathrm{O}_{3}$-water & $20-60$ & 45 \\
\hline
\end{tabular}

Table 4 Summary of empirical models for viscosity of nanofluids

\begin{tabular}{|c|c|c|}
\hline Author & Empirical model & Remarks \\
\hline Einstein [45] & $\mu_{n f}=(1+2.5 \varnothing) \mu_{b f}$ & Infinite dilution of spherical, and rigid nanoparticles devoid of any attractive forces \\
\hline Mooney [90] & $\mu_{n f}=\exp \left[\frac{2.5 \phi}{1-\left(\phi / \phi_{m}\right)}\right] \mu_{b f}$ & Einstein's model extended to apply to a suspension of finite concentration \\
\hline Brinkman [91] & $\mu_{n f}=\exp \left[\frac{1}{(1-\phi)^{2.5}}\right] \mu_{b f}$ & Modified Einstein model of spherical particles extended up to $4 \%$ volume concentration \\
\hline Batchelor [92] & $\mu_{n f}=(1+2.5 \phi+6.2) \mu_{b f}$ & Considered large nanoparticle concentration up to $10 \%$ \\
\hline $\begin{array}{l}\text { Krieger and Dough- } \\
\text { erty [46] }\end{array}$ & $\mu_{n f}=\left(1-\frac{\phi}{\phi_{m}}\right)^{-\eta \phi_{m}} \mu_{b f}$ & Considered the full range of particle volume fraction \\
\hline
\end{tabular}




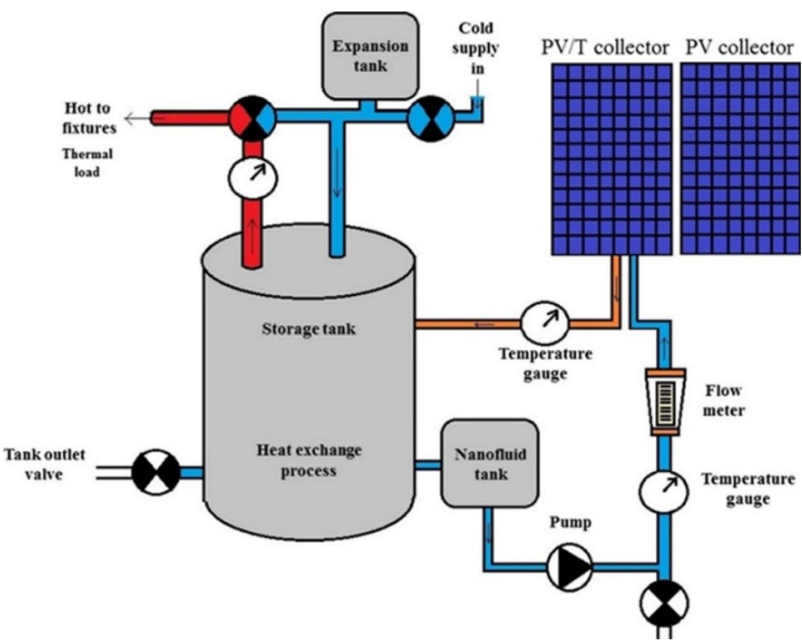

Fig. 4 A schematic diagram of the experimental rig [52]. Reproduced with permission from Elsevier

a year $(4.1 \times 1020 \mathrm{~J})$. They added that $120,000 \mathrm{TW}$ of radiation arrives at the surface of the Earth, far exceeding human needs even in the most aggressive energy demand scenarios. However, many solar capture devices suffer from relatively low collection efficiencies. Recent studies [48, 49] indicate that nanofluids can be used specifically in low optical and thermal performance solar energy conversion systems to boost their performance.

Kabeel et al. [50] investigated thermal solar water heater with $\mathrm{Al}_{2} \mathrm{O}_{3} / \mathrm{H}_{2} \mathrm{O}$ nanofluid in forced convection, and their results showed an increased solar collector efficiency of $11 \%$ for $3 \%$ nanoparticle concentration. An enhancement of $21 \%$ in average heat transfer coefficient was reported by Ebrahimnia et al. [51] after conducting laminar flow convective heat transfer experiments of water-based $\mathrm{TiO}_{2}$ nanofluid flowing through a uniformly heated tube.

Al-Waeli et al. [52] conducted an experimental investigation of $\mathrm{SiC} /$ water nanofluid as a working fluid for a

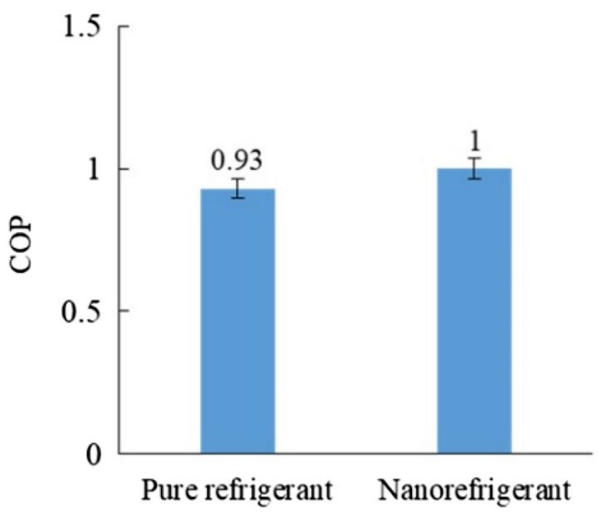

Fig. 6 Comparison of the coefficient of performance, Sanukrishna et al. [30]. Reproduced with permission from Springer

photovoltaic/thermal (PV/T) system (Fig. 4). They concluded that the thermal conductivity was enhanced by up to $8.2 \%$ for the temperature range of $25-60{ }^{\circ} \mathrm{C}$, and the thermal efficiency of the collector was increased by up to $100.19 \%$ compared to the efficiency when water was used as the working fluid.

Luo et al. [53] investigated thermal energy storage enhancement of a binary molten salt nanoparticles. They observed $4.71 \%$ enhancement of the total storage capacity at temperature range of $160-300{ }^{\circ} \mathrm{C}$. Their results also indicated an improvement in specific heat of the nanosalt by $11.48 \%$.

With these promising results, it seems likely that solar energy capture devices may be one of the first applications to have the wide spread uptake of nanofluids technology, although the stability of nanofluids remains a significant barrier.
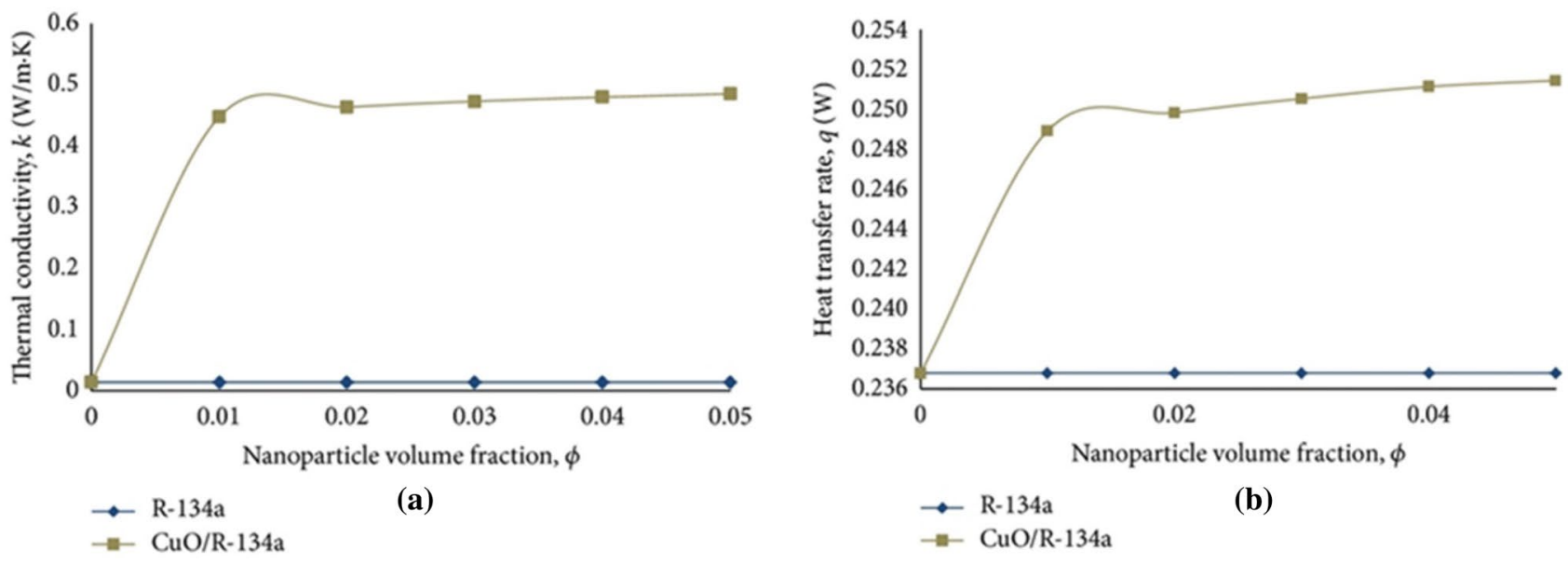

Fig. 5 Thermal conductivity (a) and heat transfer rate (b) as function of nanoparticle volume fraction, Fadhilah et al. [60] 
Fig. 7 Experimental setup for condensation-evaporation alternation, Lin et al. [61].

Reproduced with permission from Elsevier

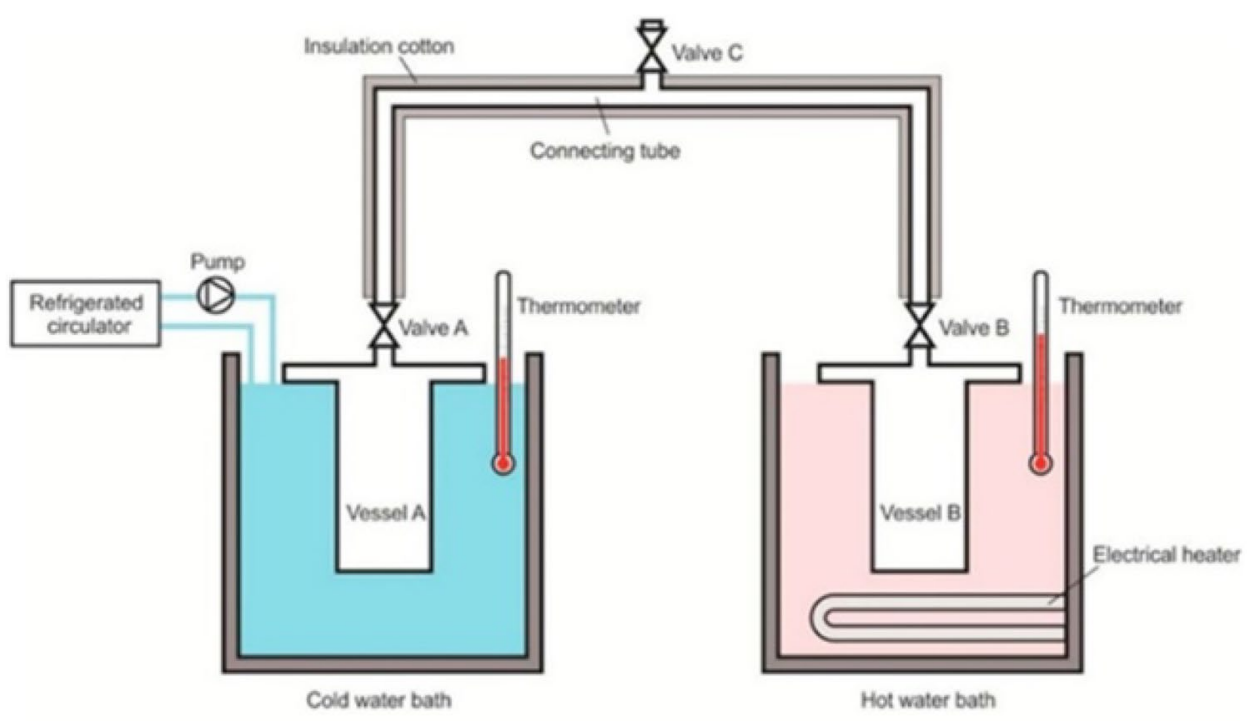

(a) Schematic diagram.

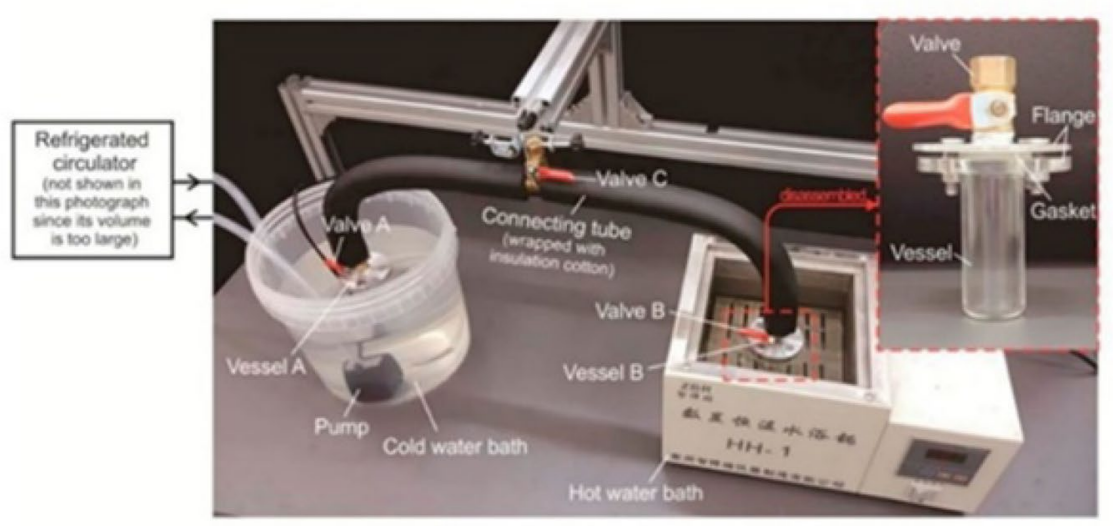

(b) Photographic view.

\section{Nanorefrigerants}

The refrigeration industry is progressively making efforts to replace traditional refrigerants with ones that have less impact on the environment. However, studies on potential replacements such as R1234ze or R1234yf or R450A have indicated that they yield lower heat transfer performance than the refrigerants they are intended to replace $[54,55]$. Therefore, the suspension of solid nanoparticles in low performing heat transfer refrigerants produces a solution termed

Table 6 A summary of additional research on nanorefrigerants

\begin{tabular}{|c|c|c|}
\hline Author & Nanorefrigerant & Results \\
\hline Lim et al. [58] & $\mathrm{Al}_{2} \mathrm{O}_{3} /$ water-EG & Convective heat transfer coefficient enhanced by $25.4 \%$ \\
\hline Redhwan et al. [96] & $\begin{array}{l}\mathrm{Al}_{2} \mathrm{O}_{3} / \mathrm{PAG} \\
\mathrm{SiO}_{2} / \mathrm{PAG}\end{array}$ & Enhancement was 1.04 times higher than the base lubricant \\
\hline Wang et al. [97] & $\mathrm{Al}_{2} \mathrm{O}_{3} / \mathrm{R}-22$ & $\begin{array}{l}\text { Nanoparticles can enhance the heat transfer characteristic of the refrigerant, } \\
\text { and the bubble size diminishes and moves quickly near the heat transfer } \\
\text { surface }\end{array}$ \\
\hline Jiang et al. [98] & CNT-R-113 & $\begin{array}{l}\text { Measured thermal conductivities of four kinds of } 1.0 \text { vol. \% CNT- R113 } \\
\text { nanorefrigerant increase to } 82 \%, 104 \%, 43 \% \text { and } 50 \% \text {, respectively }\end{array}$ \\
\hline Tazarv et al. [99] & $\mathrm{TiO}_{2} / \mathrm{R}-141 \mathrm{~B}$ & Enhancement of convective heat transfer coefficient and higher vapour qualities \\
\hline
\end{tabular}




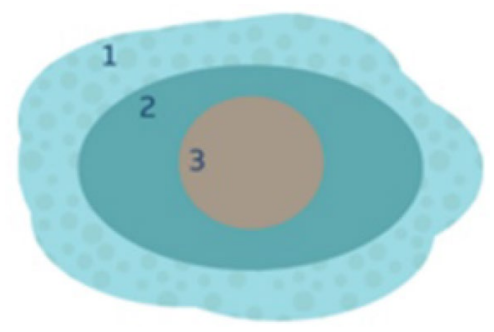

Fig. 8 Structure of nanoparticle in the base fluid. Molecules of the liquid (1) can form a specific, highly ordered layer (2) near the nanoparticle surface (3) [66]. Reproduced with permission from ACS publications

'nanorefrigerant' that can enhance refrigeration system performance. Several experimental and numerical investigations [56-59] have concluded that nanorefrigerants improve thermophysical properties, energy efficiency and the overall system performance. For instance, Fig. 5 indicates that the thermal conductivity and heat transfer of nanorefrigerant $(\mathrm{CuO} / \mathrm{R}-$ 134a) are higher than R-134a alone [60].

Sanukrishna et al. [30] dispersed copper oxide nanoparticles in R-134a and polyalkylene glycol. Their results revealed $12.67 \%$ increase in thermal conductivity and a flow boiling heat transfer enhancement of $37 \%$. The coefficient of performance (COP) of nanorefrigerant was $7.5 \%$ higher than pure refrigerant as shown in Fig. 6.

However, Lin et al. [61] carried out an experiment (Fig. 7) to evaluate the degradation of a nanolubricant-refrigerant mixture during continuously alternating condensation and evaporation processes. They discovered that the mixture degrades by $28-77 \%$ after 20 cycles for nanoparticle concentrations of $0.2-1.0 \%$, heating and temperature of $50-80^{\circ} \mathrm{C}$ and $5-15{ }^{\circ} \mathrm{C}$, respectively. They concluded that degradation would be reduced by low heating and cooling temperatures, and low nanoparticle concentrations.

Lin et al. [62] conducted an experiment using $\mathrm{TiO}_{2}$ nanoparticles and concluded that only a small fraction of the total number of nanoparticles circulate by migration from the mixture to vapour with refrigerant dry-out process. Lee et al. [63]. concluded that nanoparticles should not be used in two-phase micro-channel heat sinks due to the clustering phenomenon that propagates upstream to fill the entire channel, thus preventing coolant from entering the heat sink and causing catastrophic failure of the cooling system.

It appears, therefore, that the use of nanofluids in two-phase flow has more technological hurdles to overcome than for single-phase applications (Table 6).

\section{Current challenges and the future of nanofluids}

Despite the promising heat transfer enhancement potential observed by many researchers, there are several barriers to widespread implementation in industrial settings. Most studies on nanofluids largely rely on commercially available nanoparticles. Nanoparticles are not cheap and there is no standard price for these particles as at present (for example, at the time of writing, $100 \mathrm{~g}$ of the commonly studied alumina or copper oxide nanoparticles cost $\$ 492.00$ and $\$ 80.00$ US dollars, respectively [64]). In addition, it seems that the properties of nanoparticles differ according to the manufacturer, which adds to the uncertainty of physical property data. Equally important, some nanomaterials are toxic and therefore extra measures taken in preparation increase production cost. Mahian et al. [65] explained that challenges such as the high cost of nanoparticles, instability and agglomeration, pumping power and pressure drop, erosion and corrosion of components make nanofluid usage commercially unattractive. However, they concluded that the general application of nanofluids is still in its infant stages and, therefore, future investigations will increase the potential applications of nanofluids.

Nanofluids experience a number of effective forces during and after suspension such as drag, thermophoresis, Brownian, Van der Waals and electric double layer forces. Interfacial layers (Fig. 8) can build bridges between nanoparticles within the base fluid molecules, reducing their effectiveness [66]. This is a major challenge with no solution cited in the

Fig. 9 Suspension and stability

of nanoparticles

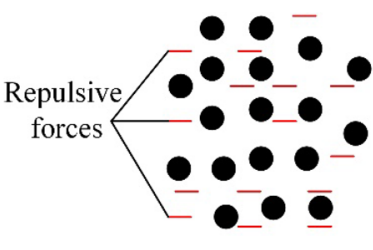

Stable suspension

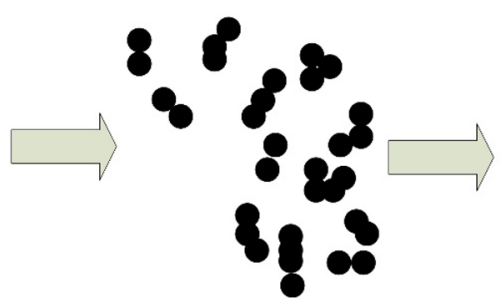

Agglomeration

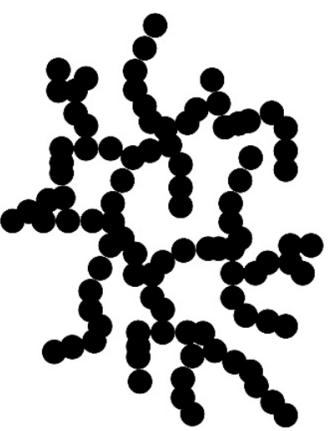

Unstable Suspension 
current literature, yet is one of the primary factors that many researchers think it contributes to aggregation and subsequent sedimentation [67-69].

The sedimentation of nanoparticles over time (Fig. 9) is still a major challenge [70-73] that needs to be overcome before there can be widespread uptake of nanofluids [48]. Simple methods have been proposed such as adding stabilising agents (surfactants) to the base fluid before the suspension of nanoparticles to lower the interfacial forces between the fluid molecules and the nanoparticles. However, even with the addition of surfactants there is no guarantee of permanent stability.

In short, the use of nanofluids in a wide range of applications appears to be growing steadily. However, currently it appears that material scientists and chemists perform most investigations of nanofluids characterisation, whereas thermal and mechanical engineering researchers carry the experiments on the application of nanofluids, and there is not always close collaboration or communication between the two groups, which may contribute to the agreements of results. Yu et al. [74] suggested that a systematic summary of dispersing strategies of nanofluids in thermal applications is needed to provide general guideline on the preparation and characterization of stably dispersed thermal nanofluids, and also to help bridge the gap between researchers in different disciplines.

Despite the fact that the field of nanofluids is still in the infancy, the future of nanofluids seems promising. Apart from solar and refrigeration applications, industrial and research institutions have progressively gained interest in the usage of nanofluids in other applications [75] including drug delivery for cancer treatment [76] and surface and subsurface defect sensors [77]. It is clear based on the review of the recent literature that significant efforts continue to be devoted to theoretical and experimental studies to improve the general performance and potential applications of nanofluids. In addition, efforts are being made to reduce the production costs of nanofluids by developing large-scale production methods $[17,78]$, and to improve the stability of nanofluids $[79,80]$.

\section{Conclusion}

This paper has reviewed experimental and theoretical developments of nanofluids in different applications. The challenges and the future insights about the potential usage of nanofluids have been discussed. The following major conclusions are drawn from this review study:

- There are wide ranges in heat transfer enhancements data reported by different studies.
- There is no universal formulation of nanofluids which may contribute to the wide range of physical property data reported, as well as wide ranges in price.

- Stability tests reveal there is currently no solution to the sedimentation of nanoparticles over time; however, stabilising agents, such as surfactants, have been shown to improve stability significantly.

- Nanofluids have a wide range of potential applications for heat transfer enhancement, with solar thermal, and refrigeration applications in particular currently being the focus of many studies.

\section{Compliance with ethical standards}

Conflict of interest The authors declare that they have no conflict of interest.

Open Access This article is distributed under the terms of the Creative Commons Attribution 4.0 International License (http://creativeco mmons.org/licenses/by/4.0/), which permits unrestricted use, distribution, and reproduction in any medium, provided you give appropriate credit to the original author(s) and the source, provide a link to the Creative Commons license, and indicate if changes were made.

\section{References}

1. Khaled, A.R.A., Siddique, M., Abdulhafiz, N.I., Boukhary, A.Y.: Recent advances in heat transfer enhancements: a review report. Int. J. Chem. Eng. (2010). https://doi.org/10.1155/2010/106461

2. Léal, L., Miscevic, M., Lavieille, P., Amokrane, M., Pigache, F., Topin, F., Nogarède, B., Tadrist, L.: An overview of heat transfer enhancement methods and new perspectives: focus on active methods using electroactive materials. Int. J. Heat Mass Transf. 61, 505-524 (2013). https://doi.org/10.1016/j.ijheatmasstrans fer.2013.01.083

3. Sheikholeslami, M., Gorji-Bandpy, M., Ganji, D.D.: Review of heat transfer enhancement methods: focus on passive methods using swirl flow devices. Renew. Sustain. Energy Rev. 49, 444469 (2015). https://doi.org/10.1016/j.rser.2015.04.113

4. Grassi, W., Testi, D.: Heat transfer enhancement by electric fields in several heat exchange regimes. Ann. NY Acad. Sci. 1077, 527569 (2006). https://doi.org/10.1196/annals.1362.062

5. Choi, S.U.S., Eastman, J.A.: Enhancing thermal conductivity of fluids with nanoparticles. ASME Int. Mech. Eng. Congr. Expo. 66, 99-105 (1995). https://doi.org/10.1115/1.1532008

6. Eastman, J.A., Choi, S.U.S., Li, S., Yu, W., Thompson, L.J.: Anomalously increased effective thermal conductivities of ethylene glycol-based nanofluids containing copper nanoparticles. Appl. Phys. Lett. 78, 718-720 (2001). https://doi. org/10.1063/1.1341218

7. Alawi, O.A., Sidik, N.A.C., Kherbeet, A.S.: Nanorefrigerant effects in heat transfer performance and energy consumption reduction: a review. Int. Commun. Heat Mass Transf. 69, 76-83 (2015). https://doi.org/10.1016/j.icheatmasstransfer.2015.10.009

8. Lefebvre, D., Tezel, F.H.: A review of energy storage technologies with a focus on adsorption thermal energy storage processes for 
heating applications. Renew. Sustain. Energy Rev. 67, 116-125 (2017). https://doi.org/10.1016/j.rser.2016.08.019

9. Gorji, T.B., Ranjbar, A.A.: A review on optical properties and application of nanofluids in direct absorption solar collectors (DASCs). Renew. Sustain. Energy Rev. 72, 10-32 (2017). https ://doi.org/10.1016/j.rser.2017.01.015

10. Kasaeian, A., Eshghi, A.T., Sameti, M.: A review on the applications of nanofluids in solar energy systems. Renew. Sustain. Energy Rev. 43, 584-598 (2015). https://doi.org/10.1016/j. rser.2014.11.020

11. Khairul, M.A., Alim, M.A., Mahbubul, I.M., Saidur, R., Hepbasli, A., Hossain, A.: Heat transfer performance and exergy analyses of a corrugated plate heat exchanger using metal oxide nanofluids. Int. Commun. Heat Mass Transf. 50, 8-14 (2014). https://doi. org/10.1016/j.icheatmasstransfer.2013.11.006

12. Lee, S.L., Saidur, R., Sabri, M.F.M., Min, T.K.: Effects of the particle size and temperature on the efficiency of nanofluids using molecular dynamic simulation. Numer. Heat Transf. A Appl. 69, 996-1013 (2016). https://doi.org/10.1080/10407782.2015.11093 69

13. Harikrishnan, A.R., Das, S.K., Agnihotri, P.K., Dhar, P.: Particle and surfactant interactions effected polar and dispersive components of interfacial energy in nanocolloids. J. Appl. Phys. (2017). https://doi.org/10.1063/1.4997123

14. Chen, H., Witharana, S., Jin, Y., Kim, C., Ding, Y.: Predicting thermal conductivity of liquid suspensions of nanoparticles (nanofluids) based on rheology. Particuology. 7, 151-157 (2009). https ://doi.org/10.1016/j.partic.2009.01.005

15. Deepak Selvakumar, R., Dhinakaran, S.: A multi-level homogenization model for thermal conductivity of nanofluids based on particle size distribution (PSD) analysis. Powder Technol. 301, 310-317 (2016). https://doi.org/10.1016/j.powtec.2016.05.049

16. Sharma, B., Sharma, S.K., Gupta, S.M.: Preparation and evaluation of stable nanofluids for heat transfer application: a review. Exp. Therm. Fluid Sci. 79, 202-212 (2016). https://doi. org/10.1016/j.expthermflusci.2016.06.029

17. Haddad, Z., Abid, C., Oztop, H.F., Mataoui, A.: A review on how the researchers prepare their nanofluids. Int. J. Therm. Sci. 76, 168-189 (2014). https://doi.org/10.1016/j.ijthermals ci.2013.08.010

18. Sidik, N.A.C., Mohammed, H.A., Alawi, O.A., Samion, S.: A review on preparation methods and challenges of nanofluids. Int. Commun. Heat Mass Transf. 54, 115-125 (2014). https://doi. org/10.1016/j.icheatmasstransfer.2014.03.002

19. Li, Y., Zhou, J., Tung, S., Schneider, E., Xi, S.: A review on development of nanofluid preparation and characterization. Powder Technol. 196, 89-101 (2009). https://doi.org/10.1016/j.powte c. 2009.07.025

20. Maxwell, J.C.: A treatise on electricity and magnetism, vol. 1. Oxford University Press, Cambridge (1873) (ISBN 13: 9780198503736)

21. Hamilton, R.L., Crosser, O.K.: Thermal conductivity of heterogeneous two-component systems. Ind. Eng. Chem. Fundam. 1, 187-191 (1962). https://doi.org/10.1021/i160003a005

22. Carson, J.K., Lovatt, S.J., Tanner, D.J., Cleland, A.C.: Thermal conductivity bounds for isotropic, porous materials. Int. J. Heat Mass Transf. 48, 2150-2158 (2005). https://doi.org/10.1016/J. IJHEATMASSTRANSFER.2004.12.032

23. Lee, S., Choi, S.U.-S., Li, S., Eastman, J.A.: Measuring thermal conductivity of fluids containing oxide nanoparticles. J. Heat Transf. 121, 280 (1999). https://doi.org/10.1115/1.2825978

24. Xing, M., Yu, J., Wang, R.: Experimental investigation and modelling on the thermal conductivity of CNTs based nanofluids. Int. J. Therm. Sci. 104, 404-411 (2016). https://doi.org/10.1016/j.ijthe rmalsci.2016.01.024
25. Jiang, W., Du, K., Li, Y., Yang, L.: Experimental investigation on influence of high temperature on viscosity, thermal conductivity and absorbance of ammonia-water nanofluids. Int. J. Refrig. 82, 189-198 (2017). https://doi.org/10.1016/j.ijrefrig.2017.05.030

26. Leong, K.Y., Razali, I., Ku Ahmad, K.Z., Ong, H.C., Ghazali, M.J., Abdul Rahman, M.R.: Thermal conductivity of an ethylene glycol/water-based nanofluid with copper-titanium dioxide nanoparticles: an experimental approach. Int. Commun. Heat Mass Transf. 90, 23-28 (2018). https://doi.org/10.1016/j.icheatmass transfer.2017.10.005

27. Suganthi, K.S., Rajan, K.S.: Metal oxide nanofluids: review of formulation, thermo-physical properties, mechanisms, and heat transfer performance. Renew. Sustain. Energy Rev. 76, 226-255 (2017). https://doi.org/10.1016/j.rser.2017.03.043

28. Farzaneh, H., Behzadmehr, A., Yaghoubi, M., Samimi, A., Sarvari, S.M.H.: Stability of nanofluids: molecular dynamic approach and experimental study. Energy Convers. Manag. 111, 1-14 (2016). https://doi.org/10.1016/j.enconman.2015.12.044

29. Kang, Z., Wang, L.: Effect of thermal-electric cross coupling on heat transport in nanofluids. Energies. 10, 123 (2017). https://doi. org/10.3390/en10010123

30. Sanukrishna, S.S., Vishnu, A.S., Jose Prakash, M.: Nanorefrigerants for energy efficient refrigeration systems. J. Mech. Sci. Technol. 31, 3993-4001 (2017). https://doi.org/10.1007/s1220 6-017-0746-4

31. Duangthongsuk, W., Wongwises, S.: Measurement of temperature-dependent thermal conductivity and viscosity of $\mathrm{TiO} 2$-water nanofluids. Exp. Therm. Fluid Sci. 33, 706-714 (2009). https:// doi.org/10.1016/j.expthermflusci.2009.01.005

32. Kannaiyan, S., Boobalan, C., Umasankaran, A., Ravirajan, A., Sathyan, S., Thomas, T.: Comparison of experimental and calculated thermophysical properties of alumina/cupric oxide hybrid nanofluids. J. Mol. Liq. 244, 469-477 (2017). https://doi. org/10.1016/j.molliq.2017.09.035

33. Hemmat Esfe, M., Saedodin, S., Mahian, O., Wongwises, S.: Efficiency of ferromagnetic nanoparticles suspended in ethylene glycol for applications in energy devices: effects of particle size, temperature, and concentration. Int. Commun. Heat Mass Transf. 58, 138-146 (2014). https://doi.org/10.1016/j.icheatmasstrans fer.2014.08.035

34. Ueki, Y., Aoki, T., Ueda, K., Shibahara, M.: Thermophysical properties of carbon-based material nanofluid. Int. J. Heat Mass Transf. 113, 1130-1134 (2017). https://doi.org/10.1016/j.ijhea tmasstransfer.2017.06.008

35. Lenin, R., Joy, P.A.: Studies on the role of unsaturation in the fatty acid surfactant molecule on the thermal conductivity of magnetite nanofluids. J. Colloid Interface Sci. 506, 162-168 (2017). https:// doi.org/10.1016/j.jcis.2017.07.038

36. Hussein, A.M., Kadirgama, K., Noor, M.M.: Nanoparticles suspended in ethylene glycol thermal properties and applications: an overview. Renew. Sustain. Energy Rev. 69, 1324-1330 (2016). https://doi.org/10.1016/j.rser.2016.12.047

37. Buongiorno, J.: convective transport in nanofluids. J. Heat Transf. 128, 240 (2006). https://doi.org/10.1115/1.2150834

38. Maïga, S.E.B., Nguyen, C.T., Galanis, N., Roy, G.: Heat transfer behaviours of nanofluids in a uniformly heated tube. Superlattices Microstruct. 35, 543-557 (2004). https://doi.org/10.1016/j. spmi.2003.09.012

39. Yang, L., Xu, J., Du, K., Zhang, X.: Recent developments on viscosity and thermal conductivity of nanofluids. Powder Technol. 317, 348-369 (2017). https://doi.org/10.1016/j.powte c. 2017.04.061

40. Namburu, P.K., Kulkarni, D.P., Misra, D., Das, D.K.: Viscosity of copper oxide nanoparticles dispersed in ethylene glycol and water mixture. Exp. Therm. Fluid Sci. 32, 397-402 (2007). https://doi. org/10.1016/j.expthermflusci.2007.05.001 
41. Hemmat Esfe, M., Saedodin, S.: An experimental investigation and new correlation of viscosity of $\mathrm{ZnO}-\mathrm{EG}$ nanofluid at various temperatures and different solid volume fractions. Exp. Therm. Fluid Sci. 55, 1-5 (2014). https://doi.org/10.1016/j.expthermfl usci.2014.02.011

42. Mariano, A., Pastoriza-Gallego, M.J., Lugo, L., Mussari, L., Piñeiro, M.M.: Co3O4 ethylene glycol-based nanofluids: thermal conductivity, viscosity and high pressure density. Int. J. Heat Mass Transf. 85, 54-60 (2015). https://doi.org/10.1016/j.ijhea tmasstransfer.2015.01.061

43. Yu, W., France, D.M., Smith, D.S., Singh, D., Timofeeva, E.V., Routbort, J.L.: Heat transfer to a silicon carbide/water nanofluid. Int. J. Heat Mass Transf. 52, 3606-3612 (2009). https://doi. org/10.1016/j.ijheatmasstransfer.2009.02.036

44. Abdul, K., Carson, J.K., Atkin, M., Walmsley, M.: Physical properties and rheological characteristics of activated carbon nanofluids with varying filler fractions and surfactants. Appl. Mech. Mater. 884, 58-65 (2018). https://doi.org/10.4028/www.scientific .net/AMM.884.58

45. Einstein, A.: Eine neue Bestimmung der Moleküldimensionen. Ann. Phys. 324, 289-306 (1906). https://doi.org/10.1002/ andp. 19063240204

46. Krieger, I.M., Dougherty, T.J.: A mechanism for non-newtonian flow in suspensions of rigid spheres. Trans. Soc. Rheol. 3, 137152 (1959). https://doi.org/10.1122/1.548848

47. Lewis, N.S., Crabtree, G., Nozik, A.J., Wasielewski, M.R., Alivisatos, P.: Basic research needs for solar energy utilization. Basic Energy Sci. Work. Sol. Energy Util. (2005). https://doi. org/10.2172/899136

48. Colangelo, G., Favale, E., De Risi, A., Laforgia, D.: A new solution for reduced sedimentation flat panel solar thermal collector using nanofluids. Appl. Energy 111, 80-93 (2013). https://doi. org/10.1016/j.apenergy.2013.04.069

49. Alim, M.A., Abdin, Z., Saidur, R., Hepbasli, A., Khairul, M.A., Rahim, N.A.: Analyses of entropy generation and pressure drop for a conventional flat plate solar collector using different types of metal oxide nanofluids. Energy Build. 66, 289-296 (2013). https ://doi.org/10.1016/j.enbuild.2013.07.027

50. Kabeel, A.E., El-Said, E.M.S., Abdulaziz, M.: Thermal solar water heater with $\mathrm{H} 2 \mathrm{O}-\mathrm{Al} 2 \mathrm{O} 3$ nano-fluid in forced convection: experimental investigation. Int. J. Ambient Energy 0750, 1-9 (2015). https://doi.org/10.1080/01430750.2015.1041653

51. Ebrahimnia-Bajestan, E., Charjouei Moghadam, M., Niazmand, H., Daungthongsuk, W., Wongwises, S.: Experimental and numerical investigation of nanofluids heat transfer characteristics for application in solar heat exchangers. Int. J. Heat Mass Transf. 92, 1041-1052 (2016). https://doi.org/10.1016/j.ijheatmasstrans fer.2015.08.107

52. Al-Waeli, A.H.A., Sopian, K., Chaichan, M.T., Kazem, H.A., Hasan, H.A., Al-Shamani, A.N.: An experimental investigation of $\mathrm{SiC}$ nanofluid as a base-fluid for a photovoltaic thermal PV/T system. Energy Convers. Manag. 142, 547-558 (2017). https:// doi.org/10.1016/j.enconman.2017.03.076

53. Luo, Y., Du, X., Awad, A., Wen, D.: Thermal energy storage enhancement of a binary molten salt via in situ produced nanoparticles. Int. J. Heat Mass Transf. 104, 658-664 (2017). https:// doi.org/10.1016/j.ijheatmasstransfer.2016.09.004

54. Kaggwa, A., Wang, C.: Investigation of thermal-hydrodynamic heat transfer performance of R-1234ze and R-134a refrigerants in a microfin and smooth tube. J. Enhanc. Heat Transf. 23, 221-239 (2016). https://doi.org/10.1615/JEnhHeatTransf.2017019585

55. Mendoza-Miranda, J.M., Mota-Babiloni, A., Ramírez-Minguela, J.J., Muñoz-Carpio, V.D., Carrera-Rodríguez, M., NavarroEsbrí, J., Salazar-Hernández, C.: Comparative evaluation of R1234yf, R1234ze(E) and R450A as alternatives to R134a in a variable speed reciprocating compressor. Energy. 114, 753-766 (2016). https://doi.org/10.1016/j.energy.2016.08.050

56. Arslan, K.: Three-dimensional computational fluid dynamics modeling of TiO2/R134a nanorefrigerant. Therm. Sci. 21, 175-186 (2017). https://doi.org/10.2298/TSCI140425002A

57. Sharif, M.Z., Azmi, W.H., Redhwan, A.A.M., Mamat, R., Yusof, T.M.: Performance analysis of SiO2/PAG nanolubricant in automotive air conditioning system. Int. J. Refrig. 75, 204-216 (2017). https://doi.org/10.1016/j.ijrefrig.2017.01.004

58. Lim, S.K., Azmi, W.H., Yusoff, A.R.: Investigation of thermal conductivity and viscosity of $\mathrm{Al} 2 \mathrm{O} 3 /$ water-ethylene glycol mixture nanocoolant for cooling channel of hot-press forming die application. Int. Commun. Heat Mass Transf. 78, 182-189 (2016). https://doi.org/10.1016/j.icheatmasstrans fer.2016.09.018

59. Nair, V., Tailor, P.R., Parekh, A.D.: Nanorefrigerants: a comprehensive review on its past, present and future. Int. J. Refrig. 67, 290-307 (2016). https://doi.org/10.1016/j.ijrefrig.2016.01.011

60. Fadhilah, S.A., Marhamah, R.S., Izzat, A.H.M.: Copper oxide nanoparticles for advanced refrigerant thermophysical properties: mathematical modeling. J. Nanopart. 2014, 1-5 (2014). https:// doi.org/10.1155/2014/890751

61. Lin, L., Peng, H., Chang, Z., Ding, G.: Experimental research on degradation of nanolubricant-refrigerant mixture during continuous alternation processes of condensation and evaporation. Int. J. Refrig. 76, 97-108 (2017). https://doi.org/10.1016/j.ijref rig.2016.12.021

62. Lin, L., Peng, H., Chang, Z., Ding, G.: Experimental investigation on $\mathrm{TiO} 2$ nanoparticle migration from refrigerant-oil mixture to lubricating oil during refrigerant dryout. Int. J. Refrig. 77, 75-86 (2017). https://doi.org/10.1016/j.ijrefrig.2017.02.026

63. Lee, J., Mudawar, I.: Assessment of the effectiveness of nanofluids for single-phase and two-phase heat transfer in micro-channels. Int. J. Heat Mass Transf. 50, 452-463 (2007). https://doi. org/10.1016/j.ijheatmasstransfer.2006.08.001

64. Amorphous Products I Nanoscale Products I Nanopowder I Nanoparticles-Aluminum Oxide Powder (gamma, 99.5\% (metal basis), $80 \mathrm{~nm}$ ). https://www.nanoamor.com/inc/sdetail/50582. Accessed Dec 2017

65. Mahian, O., Kianifar, A., Kalogirou, S.A., Pop, I., Wongwises, S.: A review of the applications of nanofluids in solar energy. Int. J. Heat Mass Transf. 57, 582-594 (2013). https://doi.org/10.1016/j. ijheatmasstransfer.2012.10.037

66. Sizochenko, N., Syzochenko, M., Gajewicz, A., Leszczynski, J., Puzyn, T.: Predicting physical properties of nanofluids by computational modeling. J. Phys. Chem. C 121, 1910-1917 (2017). https://doi.org/10.1021/acs.jpcc.6b08850

67. Pal, R.: A novel method to determine the thermal conductivity of interfacial layers surrounding the nanoparticles of a nanofluid. Nanomaterials. 4, 844-855 (2014). https://doi.org/10.3390/nano4 040844

68. Machrafi, H., Lebon, G.: The role of several heat transfer mechanisms on the enhancement of thermal conductivity in nanofluids. Contin. Mech. Thermodyn. 28, 1461-1475 (2016). https://doi. org/10.1007/s00161-015-0488-4

69. Pinto, R.V., Fiorelli, F.A.S.: Review of the mechanisms responsible for heat transfer enhancement using nanofluids. Appl. Therm. Eng. 108, 720-739 (2016). https://doi.org/10.1016/j.appltherma leng.2016.07.147

70. Aref, A.H., Entezami, A.A., Erfan-Niya, H., Zaminpayma, E.: Thermophysical properties of paraffin-based electrically insulating nanofluids containing modified graphene oxide. J. Mater. Sci. 52, 2642-2660 (2017). https://doi.org/10.1007/s10853-016-0556-6

71. Chen, W., Zou, C., Li, X., Li, L.: Experimental investigation of $\mathrm{SiC}$ nanofluids for solar distillation system: stability, optical properties and thermal conductivity with saline water-based 
fluid. Int. J. Heat Mass Transf. 107, 264-270 (2017). https://doi. org/10.1016/j.ijheatmasstransfer.2016.11.048

72. Chen, L., Xie, H., Li, Y., Yu, W.: Nanofluids containing carbon nanotubes treated by mechanochemical reaction. Thermochim. Acta 477, 21-24 (2008). https://doi.org/10.1016/j.tca.2008.08.001

73. Timofeeva, E.V., Moravek, M.R., Singh, D.: Improving the heat transfer efficiency of synthetic oil with silica nanoparticles. J. Colloid Interface Sci. 364, 71-79 (2011). https://doi.org/10.1016/j. jcis.2011.08.004

74. Yu, F., Chen, Y., Liang, X., Xu, J., Lee, C., Liang, Q., Tao, P., Deng, T.: Dispersion stability of thermal dispersion stability of thermal nanofluids. Prog. Nat. Sci. Mater. Int. 27, 531-542 (2017). https://doi.org/10.1016/j.pnsc.2017.08.010

75. Bhardwaj, V., Kaushik, A.: Biomedical applications of nanotechnology and nanomaterials. Micromachines. 8, 298 (2017). https ://doi.org/10.3390/mi8100298

76. Yang, D., Yang, F., Hu, J., Long, J., Wang, C., Fu, D., Ni, Q.: Hydrophilic multi-walled carbon nanotubes decorated with magnetite nanoparticles as lymphatic targeted drug delivery vehicles. Chem. Commun. (2009). https://doi.org/10.1039/b908012k

77. Mahendran, V., Philip, J.: Naked eye visualization of naked eye visualization of defects in ferromagnetic materials and components. NDT E Int. 60, 100-109 (2013). https://doi.org/10.1016/j. ndteint.2013.07.011

78. Gharehkhani, S., Shirazi, S.F.S., Jahromi, S.P., Sookhakian, M., Baradaran, S., Yarmand, H., Oshkour, A.A., Kazi, S.N., Basirun, W.J.: Spongy nitrogen-doped activated carbonaceous hybrid derived from biomass material/graphene oxide for supercapacitor electrodes. RSC Adv. 5, 40505-40513 (2015). https://doi. org/10.1039/c5ra01525a

79. Devendiran, D.K., Amirtham, V.A.: A review on preparation, characterization, properties and applications of nanofluids. Renew. Sustain. Energy Rev. 60, 21-40 (2016). https://doi.org/10.1016/j. rser.2016.01.055

80. Fuskele, V., Sarviya, R.M.: Recent developments in nanoparticles synthesis, preparation and stability of nanofluids. Mater. Today Proc. 4, 4049-4060 (2017). https://doi.org/10.1016/j.matpr .2017.02.307

81. Pak, B.C., Cho, Y.I.: Hydrodynamic and heat transfer study of dispersed fluids with submicron metallic oxide particles. Exp. Heat Transf. 11, 151-170 (1998). https://doi.org/10.1080/0891615980 8946559

82. Mintsa, H.A., Roy, G., Nguyen, C.T., Doucet, D.: New temperature dependent thermal conductivity data for water-based nanofluids. Int. J. Therm. Sci. 48, 363-371 (2009). https://doi. org/10.1016/j.ijthermalsci.2008.03.009

83. Murshed, S.M.S., Leong, K.C., Yang, C.: Enhanced thermal conductivity of $\mathrm{TiO} 2$ - water based nanofluids. Int. J. Therm. Sci. 44, 367-373 (2005). https://doi.org/10.1016/j.ijthermals ci.2004.12.005

84. Parametthanuwat, T., Bhuwakietkumjohn, N., Rittidech, S., Ding, Y.: Experimental investigation on thermal properties of silver nanofluids. Int. J. Heat Fluid Flow 56, 80-90 (2015). https://doi. org/10.1016/j.ijheatfluidflow.2015.07.005

85. Ali, H.M., Arshad, W.: Thermal performance investigation of staggered and inline pin fin heat sinks using water based rutile and anatase $\mathrm{TiO} 2$ nanofluids. Energy Convers. Manag. 106, 793-803 (2015). https://doi.org/10.1016/j.enconman.2015.10.015

86. Karimi, A., Sadatlu, M.A.A., Saberi, B., Shariatmadar, H., Ashjaee, M.: Experimental investigation on thermal conductivity of water based nickel ferrite nanofluids. Adv. Powder Technol. 26, 1529-1536 (2015). https://doi.org/10.1016/j.apt.2015.08.015

87. Mehrali, M., Sadeghinezhad, E., Latibari, S.T., Mehrali, M., Togun, H., Zubir, M.N.M., Kazi, S.N., Metselaar, H.S.C.: Preparation, characterization, viscosity, and thermal conductivity of nitrogen-doped graphene aqueous nanofluids. J. Mater. Sci. 49, 7156-7171 (2014). https://doi.org/10.1007/s10853-014-8424-8

88. Kole, M., Dey, T.K.: Investigation of thermal conductivity, viscosity, and electrical conductivity of graphene based nanofluids. J. Appl. Phys. (2013). https://doi.org/10.1063/1.4793581

89. Branson, B.T., Beauchamp, P.S., Beam, J.C., Lukehart, C.M., Davidson, J.L.: Nanodiamond nanofluids for enhanced thermal conductivity. ACS Nano 7, 3183-3189 (2013). https://doi. org/10.1021/nn305664x

90. Mooney, M.: The viscosity of a concentrated suspension of spherical particles. J. Colloid Sci. 6, 162-170 (1951). https://doi. org/10.1016/0095-8522(51)90036-0

91. Brinkman, H.C.: The viscosity of concentrated suspensions and solutions. J. Chem. Phys. 20, 571-571 (1952). https://doi. org/10.1063/1.1700493

92. Batchelor, G.K.: The effect of Brownian motion on the bulk stress in a suspension of spherical particles. J. Fluid Mech. 83, 97 (1977). https://doi.org/10.1017/S0022112077001062

93. He, Y., Jin, Y., Chen, H., Ding, Y., Cang, D., Lu, H.: Heat transfer and flow behaviour of aqueous suspensions of $\mathrm{TiO} 2$ nanoparticles (nanofluids) flowing upward through a vertical pipe. Int. J. Heat Mass Transf. 50, 2272-2281 (2007). https://doi.org/10.1016/j. ijheatmasstransfer.2006.10.024

94. Ding, Y., Alias, H., Wen, D., Williams, R.A.: Heat transfer of aqueous suspensions of carbon nanotubes (CNT nanofluids). Int. J. Heat Mass Transf. 49, 240-250 (2006). https://doi.org/10.1016/j. ijheatmasstransfer.2005.07.009

95. Das, S.K., Putra, N., Roetzel, W.: Pool boiling characteristics of nano-fluids. Int. J. Heat Mass Transf. 46, 851-862 (2003). https ://doi.org/10.1016/S0017-9310(02)00348-4

96. Redhwan, A.A.M., Azmi, W.H., Sharif, M.Z., Zawawi, N.N.M.: Thermal conductivity enhancement of $\mathrm{Al} 2 \mathrm{O} 3$ and $\mathrm{SiO} 2$ nanolubricants for application in automotive air conditioning (AAC) system A.A.M. MATEC Web Conf. 90, 01051 (2017). https://doi. org/10.1016/j.jirefrig.2016.06.025

97. Wang, K.J., Ding, G.L., Jiang, W.T.: Nano-scale thermal transporting and its use in engineering. In: Proceedings of the 4th Symposium on Refrigeration and Air Condition, pp. 66-75 (2006)

98. Jiang, W., Ding, G., Peng, H.: Measurement and model on thermal conductivities of carbon nanotube nanorefrigerants. Int. J. Therm. Sci. 48, 1108-1115 (2009). https://doi.org/10.1016/j.ijthermals ci.2008.11.012

99. Tazarv, S., Saffar-Avval, M., Khalvati, F., Mirzaee, E., Mansoori, $Z$.: Experimental investigation of saturated flow boiling heat transfer to $\mathrm{TiO}_{2} / \mathrm{R} 141 \mathrm{~b}$ nanorefrigerant. Exp. Heat Transf. (2016). https ://doi.org/10.1080/08916152.2014.973976

Publisher's Note Springer Nature remains neutral with regard to jurisdictional claims in published maps and institutional affiliations. 